\title{
Fetal Heart Evaluation
}

\section{Fetal Kalp Değerlendirmesi}

\section{(1) Barış SEVER, (1) Halil Gürsoy PALA}

University of Health Sciences Turkey, İzmir Tepecik Training and Research Hospital, Clinic of Obstetrics and Gynecology, Division of Perinatology, İzmir, Turkey

Cite as: Sever B, Pala HG. Fetal Heart Evaluation. Forbes J Med. 2021;2(3):142-149.

\begin{abstract}
Congenital heart diseases are considered the most common fetal anomalies. While some of these anomalies may have a minimal impact on the life of a newborn, some may result in neonatal deaths in the early period. With early diagnosis, detection of anomalies that are incompatible with life and termination of pregnancy with the consent of the patient can be offered as options. In addition, since many cardiac anomalies are treated during the postpartum period, it is important to detect those having this type of anomaly and offer them an early and appropriate treatment option during the postpartum period. It is highly appropriate to have delivery in hospitals that are technically equipped to handle cardiac anomalies. For these reasons, fetal cardiac evaluations are now being performed recently. Technical difficulties, inability to spare enough time for the patient or lack of experience in the cardiac evaluation may facilitate the lack of detection of fetal heart anomalies. Cardiac anomalies are among the most undetected anomalies. Although it may seem like a very difficult evaluation at first, fetal cardiac evaluation is actually a very simple and easy to perform examination. By creating a certain algorithm, the most common cardiac anomalies can be detected easily. Each clinician should establish a certain order according to their own physical conditions and the basic structures to be considered should be evaluated in this order. In this article, we present suggestions on how to perform a fetal cardiac evaluation using current approaches.
\end{abstract} Keywords: Congenital heart diseases, fetal cardiac anomaly, fetal cardiac evaluation

öz

Konjenital kalp hastalıkları en sık görülen fetal anomalilerdir. Bu anomalilerden bazıları yenidoğanın yaşamına minimal düzeyde etki edebilecekken, bazıları ise erken dönemde yenidoğan ölümlerine kadar gidebilmektedir. Erken dönemde tanı ile, yaşamla bağdaşmayan anomalilerin saptanması ve hastanın onayı ile gebeliğin sonlandırılması seçeneği sunulabilmektedir. Ayrıca birçok kardiyak anomalinin postpartum dönemde tedavisinin olması nedeniyle, bu tip anomalisi olanların saptanarak, postpartum dönemde erken ve uygun tedavi seçeneğinin gebeye sunulabilmesi önemlidir. Kardiyak anomalilere müdahale edebilecek teknik donanımın olduğu hastanelerde doğumun olması en uygun tercihtir. Tüm bu nedenlerden dolayı fetal kardiyak değerlendirme son zamanlarda güncel olarak yapılmaktadır. Teknik zorluklar, hastaya yeterli vakit ayrılamaması veya kardiyak değerlendirmede tecrübe eksikliği, fetal kalp anomalilerinin yakalanamamasına neden olmaktadır. Kardiyak anomaliler en çok yakalanamayan anomalilerin başında gelmektedir. İlk etapta çok zor bir muayene gibi gözükse de, fetal kardiyak değerlendirme aslında çok basit ve uygulanması kolay bir incelemedir. Belli bir algoritma oluşturarak, en sık görülen kardiyak anomaliler kolaylıkla saptanabilmektedir. Her klinisyen kendi fiziki şartlarına göre belli bir sıralama oluşturmalı ve bakılması gereken temel yapıları, bu sıra ile değerlendirilmelidir. Bu yazımızda, fetal kardiyak değerlendirmenin güncel yaklaşımlar eşliğinde nasıl yapılacağına dair öneriler sunduk.

Anahtar Kelimeler: Konjenital kalp hastalıkları, fetal kardiyak anomali, fetal kardiyak değerlendirme
Received/Geliș: 27.07.202

Accepted/Kabul: 24.08.2021

Corresponding Author/ Sorumlu Yazar:

Barış Sever MD,

University of Health Sciences Turkey. İzmir Tepecik Training and Research Hospital, Clinic of Obstetrics and Gynecology, Division of Perinatology, İzmir, Turkey

Phone: +90 5324635384

drbarissever@gmail.com ORCID: 0000-0002-9690-8819

\footnotetext{
${ }^{\circ}$ Copyright 2021 by the İzmir Buca Seyfi Demirsoy Training and Research Hospital / Forbes Journal of Medicine published by Galenos Publishing House. Licensed by Creative Commons Attribution 4.0 International (CC BY)

${ }^{\circ}$ Telif Hakkı 2021 İzmir Buca Seyfi Demirsoy Eğitim ve Araştırma Hastanesi / Forbes Tıp Dergisi, Galenos Yayınevi tarafından yayınlanmıştır Bu dergide yayınlanan bütün makaleler Creative Commons 4.0 Uluslararası Lisansı (CC-BY) ile lisanslanmıștır.
} 


\section{INTRODUCTION}

Congenital heart diseases (CHDs) are considered the most common congenital anomalies in humans. ${ }^{1.2}$ The approximate incidence is 6 per 1000 births. CHDs account for approximately $40 \%$ of perinatal deaths. ${ }^{3}$ Approximately $20 \%$ of these perinatal deaths occur in the first month of the postnatal period. ${ }^{4}$ Therefore, CHDs pose both a financialpsychological problem for the family and a serious economic burden on the health system. Fetal cardiac evaluation is the only method for detecting CHD prenatally.

\section{Scan Sections}

A cardiac examination is not a very difficult ultrasound conducted in every ultrasonographic examination. Although it will be discussed in detail in the following sections, as a brief summary, it is possible to detect approximately 80$85 \%$ of the anomalies that may occur in the heart by taking five transverse sections in the heart examination. If these sections are specified in the order:

1) Situs (starts with abdominal circumference),

2) Four-chamber view (transverse section in thoracic section),

3) Aorta-left ventricular outflow tract,

4) Right ventricular outflow tract,

5) Three-vessel trachea section. ${ }^{5}$

Ventricular septal defect, atrial septal defect, mild pulmonary stenosis, mild aortic stenosis, or stenotic lesions occurring in the following weeks are cardiac anomalies that may be undetected in these five sections.

It is necessary to conduct a systematic examination on the fetus before commencing the fetal heart examination. ${ }^{6.7}$ It is important to examine all other parameters before focusing on the heart in a systematic review. More specifically, care must be taken in any underlying genetic disease or systematic pathology in terms of concomitant cardiac anomaly. The detection of findings outside the heart with a detailed examination is important in terms of other accompanying pathologies. Indeed, before starting the heart examination, which is considered among the most important parts of this systematic evaluation, the knowledge of the fact that cardiac anomalies are the most common congenital anomaly is very pertinent. In addition, the most missed and undetected anomalies in the ultrasonographic examination are fetal heart anomalies. It has a high incidence rate of 6 per 1000 births. $^{3}$ It is six times more likely to occur than a disease, such as trisomy 21 , which is often the main focus in our current practice. ${ }^{8}$ In addition, it is seen four times more frequently than the risk of neural tube defect, which we tried to determine in detail in a similar way. ${ }^{9}$ Therefore, detailed screening and diagnosis of cardiac anomalies that are very common and can cause serious morbidity are important..$^{10}$ Unfortunately, the heart is one of the organs that are most difficult to scan, and accordingly, congenital heart anomalies are among the most undetected congenital anomalies on ultrasonographic examination. As we mentioned before, approximately half of the congenital heart anomalies, which have a high incidence of 6 per 1000 births, are major congenital anomalies. Such major congenital heart anomalies account for approximately $20 \%$ of neonatal deaths. Newborns with major congenital heart anomalies await a difficult process with the possibility of fetal mortality. They mostly need to be hospitalized; however, those who have the option of surgery are operated on after fetal stabilization. Indeed, the entire process has serious wearing effects on the family. Therefore, if we screen and recognize such congenital heart anomalies, we can advise the family about fetal prognosis. In addition, we can reduce fetal morbidity and mortality by enabling child delivery in centers suitable for fetal intervention."

\section{Patient Selection for Fetal Heart Evaluation}

Who should we screen for fetal CHD? The answer to this question has been much debated. ${ }^{12}$ In the pediatric council of the American Echocardiography Society, indications for echocardiography are specified for certain conditions (Table 1). ${ }^{13.14}$

Table 1. Echocardiography indications according to the American Society of Echocardiography

\begin{tabular}{|l|l|}
\hline \multirow{5}{*}{$\begin{array}{l}\text { Maternal } \\
\text { indications }\end{array}$} & Congenital heart diseases family history \\
\cline { 2 - 3 } & $\begin{array}{l}\text { Metabolic diseases } \\
\text { (diabetes, phenylketonuria, etc.) }\end{array}$ \\
\cline { 2 - 3 } & Peratogen exposure \\
\cline { 2 - 3 } & Rubella infection \\
\cline { 2 - 3 } & Autoimmune diseases (SLE, Sjögren's) \\
\cline { 2 - 3 } Fetal & $\begin{array}{l}\text { Familial inherited diseases } \\
\text { (Ellis van Creveld send., Marfan send.) }\end{array}$ \\
\cline { 2 - 3 } & In vitro fertilization \\
\hline \multirow{5}{*}{ indications } & Abnormal ultrasound image \\
\cline { 2 - 3 } & Extracardiac abnormality \\
\cline { 2 - 3 } & Chromosomal abnormality \\
\cline { 2 - 3 } & Arrhythmia \\
\cline { 2 - 3 } & Hydrops \\
\cline { 2 - 3 } & Increased nuchal translucency \\
\cline { 2 - 3 } & Multiple pregnancy \\
\cline { 2 - 3 } & Twin to twin syndrome \\
\hline
\end{tabular}


The separation of patients into low-risk or high-risk groups and performing fetal echocardiographic examination only in the high-risk group is not a very logical option, since only 10$15 \%$ of CHDs are seen in high-risk patients. In other words, most of the CHDs (80-85\%) occur in pregnant women having no risk factors. Therefore, all pregnant women should be screened for cardiac anomalies, regardless of the risk factor for CHDs.

\section{Risk Factors for Fetal Cardiac Anomaly}

In brief, the high-risk group can be divided into two groups: maternal risk group and fetal risk group. The maternal risk group can be described as follows: a) those with a family history (risk between $2 \%$ and $4 \%$ ); b) presence of metabolic diseases, such as diabetes mellitus, phenylketonuria, etc. (risk between $4 \%$ and $6 \%$ ); and c) exposure to teratogens, such as carbamazepine, lithium, retinoic acid, lithium, etc. (risk between $2 \%$ and $3 \%$ ).

Those who constitute the fetal risk group can be described as follows: a) suspected cardiac anomaly (risk between $50 \%$ and 60\%); b) abnormal fetal karyotype (risk between $17 \%$ and $48 \%$ ); c) major extracardiac anomaly (risk between $13 \%$ and $14 \%$ ); d) increased nuchal translucency (risk 5\%); and e) fetal cardiac rhythm disturbances (with a risk of $2 \%$ ). These risk groups are the indication list for fetal echocardiography of the American Fetal Echocardiography Society. In other words, fetal echocardiography was recommended to those with such conditions (risk group). An indebt look these risk groups reveals the suspicion of cardiac anomaly, which increases the risk of CHD. In other words, CHD occurs in approximately half of the cases with a suspected cardiac anomaly in any ultrasound examination as a result of fetal echocardiography. For this reason, all fetuses should be screened in terms of the heart and fetal echocardiography should not be decided based on distinctions, such as lowhigh risk group.

\section{Evaluation of the Thorax}

Fetal cardiac evaluation should commence with a thorax examination. The ideal image can be obtained when the fetus is lying on its back and when the heart is close to the ultrasound probe. If the back of the fetus is close to the ultrasound probe, the shadowing of the anterior vertebrae and costae may result in visual impairment. In such cases, it is necessary to await the return of the fetus. Scanning of the thorax is started with sagittal and transverse sections. First, the things to be checked are whether there is thoracic integrity or any defect in the vertebral and sternal region. Defects in the sternum and herniation of the heart from the intrathoracic region are the first deformities detected. In addition, vertebral anomalies (kyphosis-scoliosis) will negatively affect the development of the heart. The diaphragm should be considered a hypoechoic line on the sagittal section. This line should be followed from the beginning to the end and should be examined for any defect. The liver and stomach should be seen below this hypoechoic line and the heart above it. Especially in cases, such as diaphragmatic hernia, seeing structures, such as stomach, intestines, or liver, next to the heart is diagnostically important. Therefore, sagittal section examination should be done in thorax examination. In the transverse section, we should observe that the heart occupies one-third of the thoracic cavity and that there are echogenic lungs on both sides. We have the opportunity to evaluate the thorax during all gestational weeks. It is possible to examine both sides of the heart during all weeks of pregnancy to determine whether there is any mass, effusion, or organ that should be in the intraabdominal region other than the lungs. Perhaps one of the most important examinations in thorax examination is the thorax size. A small thorax image is an important marker for skeletal dysplasia. Pulmonary hypoplasia should be considered. Newborns birthed with such a narrow thorax have a poor prognosis as a result of lung hypoplasia. In addition, pathologies, such as pulmonary sequestration or congenital cystic adenomatoid malformations, should be considered in the hyperechoic lung image in the thorax examination.

The next in the thoracic examination step is to determine the position of the heart. We mentioned above that twothirds of the heart should be on the left side of the thorax. If it is determined that the heart is being pushed medial to the thorax or further to the right of the thorax, it may be thought that the heart has been displaced secondary to an underlying lung mass or effusion.

One of the criteria that can be used to determine the thorax size is the thorax-abdominal circumference ratio. ${ }^{15}$ Normally, this ratio should be 0.8 . At lower values, narrow thorax should be mentioned. In addition, the decrease in the angle of the transition from the thoracic region to the abdominal region at the level of the diaphragm in the sagittal section is an indication that the thorax remains small and cannot be accompanied by relative abdominal enlargement. After measuring the abdominal circumference, if we angle the probe very slightly and superiorly, the thoracic circumference and the four-chamber view of the heart will be obtained. Therefore, it is more reasonable to measure the abdominal circumference before proceeding to the thoracic sections. Another advantage of measuring the abdominal circumference first is that it aids the understanding of the 
location of the stomach, aorta, and inferior vena cava in terms of the side of the heart they should be found. It also helps us to understand whether there are situs anomalies. Of course, one of the important points to be considered here is the necessity of taking accurate abdominal circumference measurements. Changing directly from the abdominal measurements taken from the wrong sections to the thoracic measurements may lead to incorrect thoracic evaluations. To obtain an accurate abdominal measurement, the kidneys, portal system, and stomach pocket should not be seen and a single rib should be seen on both sides. Seeing the ribs on the cut-off of both sides indicates that we are on the wrong plane. Another important point in thoracic evaluation is the amount of fetal amniotic fluid. Fetal intrathoracic masses may cause polyhydramnios since they impair the swallowing function. Intrathoracic evaluation should be conducted in detail while investigating the etiology in cases with polyhydramnios.

\section{Determination of Fetal Position}

An important determination to be done after the thoracic evaluation is the position of the fetus in the uterus. ${ }^{16}$ The right and left arms of the fetus should be determined and the imaginary position of the fetus should be known. Without determining the position of the fetus, we cannot understand whether the fetal structures are on the right side. The stomach should be on the left of the fetus. The umbilical vein and liver should be on the right of the fetus. In addition, the two structures located on the posterior wall of the abdomen should be seen. The first structure, which is the aorta, is located more posteriorly and to the left. The other anechoic structure is the inferior vena cava, which is located just anterior to the aorta. When an anomaly is determined in the settlements of the structures that should be seen here, situs anomalies are usually the first suspicion.

\section{The Four-chamber View}

After taking an accurate transverse section of the abdominal circumference and determining the fetal position, a fourchamber view of the heart is obtained by angling the probe very slightly and superiorly to the fetus. A fetal cardiac examination can now be started by focusing on the heart. The first things to consider are axis-position of the heart, rhythm rate, presence of pericardial effusion, and presence of myocardial hypertrophy. In other words, when the fourchamber view is taken, the structures to be viewed should not have four room views only. In the first place, the findings listed above should be seen.

To determine the axis of the heart, two imaginary lines can be drawn from front to back and from right to left, dividing the thorax into four imaginary quadrants (Figure 1). Two-thirds of the heart must be found on the left side of the front-to-back line. ${ }^{17}$ It is pathological if it is completely pushed to the left or otherwise pushed to the right. The line drawn from the interventricular septum of the heart to the point where the two imaginary lines intersect indicates the axis of the heart. The angle between the imaginary anterior-posterior line and the interventricular line should normally be at angle of $45^{\circ}$ to the left. ${ }^{18}$ This axis is called the levocardia. If the apex of the heart is turned to the mid-right or, in other words, if the angle between the anterior-posterior line and the interventricular line is narrowed, it is called mesocardia. If the heart has rotated further to the right, this axis is also called dextrocardia and care must be taken in terms of situs anomalies. Another condition that needs to be evaluated is the position of the heart. As mentioned above, two-thirds of the heart should be located on the left and one-third in the right thorax. If the heart is completely positioned in the left thorax, it is called the levo position. If the heart is in the middle, it is called the meso position. If the heart is displaced to the right, it is called the dextro position. If the heart is in this dextro position, masses that will push the heart to the right should be considered. Diaphragmatic hernias and congenital cystic adenomatoid malformations are examples of these masses. In addition, if there is hypoplasia in any lung, it should be kept in mind that the heart may change position toward that side.

We know that to assess the size of the heart, it should occupy approximately one-third of the thorax. The small heart may be due to the lungs being larger than normal. It should be kept in mind that it may be due to obstructions in the upper airways as well as pleural effusions. The fact that the heart is larger than normal should be a warning for heart failure, intrauterine growth retardation, or congenital hypertrophic cardiomyopathies.

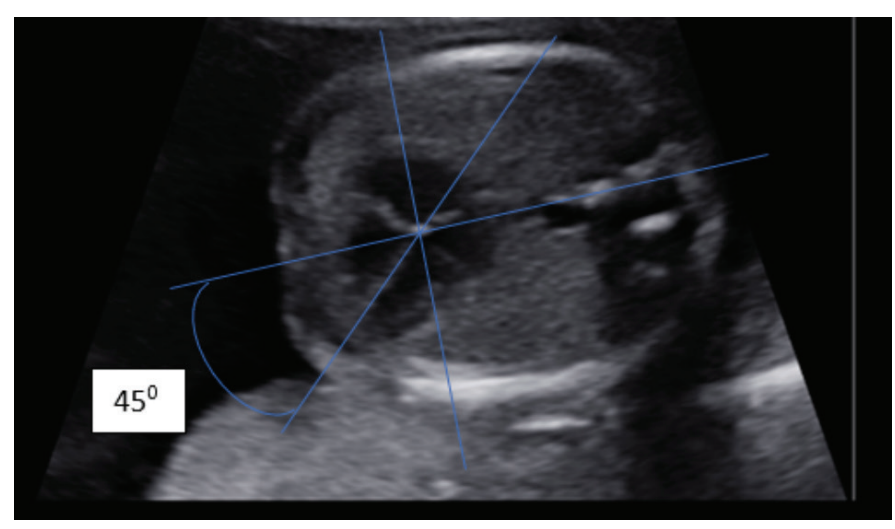

Figure 1. Determination of the axis of the heart 


\section{Rhythm-rate-pericardial Space}

It is necessary to evaluate the rate and rhythm of the heart. The heart rate should normally be between 120 and 160 beats per minute..$^{19}$ However, when it is below $100 \mathrm{bpm}$ or above $160 \mathrm{bpm}$, fetal arrhythmias should be suspected. ${ }^{20}$ In such cases, especially in tachyarrhythmias, fetal cardiac failure may occur in the following weeks and its treatment is possible. Therefore, detecting these rhythm disorders in the intrauterine period will reduce the rate of fetal morbidity.

The accumulation of more than $2 \mathrm{~mm}$ of fluid in the space between the pericardium and myocardium around the heart is considered pathological (Figure 2). ${ }^{21}$ In addition, there are studies associating the increase in fetal pericardiac adipose tissue thickness with fetal insulin resistance. ${ }^{22}$

These evaluations are the general evaluation conducted at the first stage of the heart examination. After this stage, it is now possible to proceed to a detailed heart examination. At first, the four-chamber image of the heart should be seen clearly (Figure 3). Both atria and ventricles should be viewed in the same image plane. In addition, atrioventricular valves should be evaluated clearly in this plane. The leftright distinction should be done clearly and it should be understood that the structures on the left are normally leftpositioned structures and that the structures on the right are normally right-positioned structures. There should be a level difference between the right and left atrioventricular valves. The right atrioventricular valve is called the tricuspid valve, while the left atrioventricular valve is called the mitral valve. If there is no level difference, it may refer to a common atrioventricular valve. It should be seen that the tricuspid valve is always $1-2 \mathrm{~mL}$ lower than the mitral valve (offset finding). ${ }^{14}$ The tricuspid valve is located more apically. The part of the interventricular septum under these atrioventricular valves is the part of the inlet septum. The septum just above the atrioventricular valves is the septum primum (between the two atria). Again, in cases where the

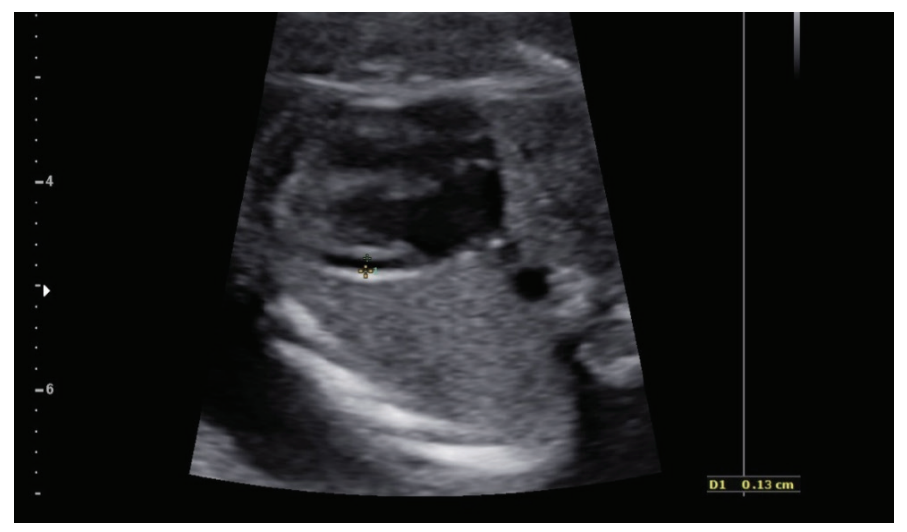

Figure 2. The effusion in the pericardial region septum primum is absent, the atrioventricular septal defect should be suspected. ${ }^{23}$ The foramen ovale between both atriums should be open. It should be seen that the flap of the foramen ovale moves from the right atrium to the left atrium. It is important to make a clear distinction between the right and left ventricles. A few small tips can help us with this. First, the structure of the right ventricle is more like a triangle because there is a structure in it. This is called a moderator band. It is actually a musculature (musculus trabeculosepto marginalis) and is found only in the right ventricle. The inner surface of the left ventricle has a smoother course and is not located in a muscular structure like the right ventricle. In this way, the right and left ventricle can be morphologically distinguished. Thus, it can be distinguished that the left ventricle of the fetus is on the left and that the right ventricle is on the right. For instance, in the transposition of the great arteries, the left-right ventricles are involved in reversed sides. The only way to detect such anomalies is to determine the inversion between these ventricles. Both ventricles should be approximately equal in size..$^{24}$ Although the left ventricle appears larger, this image originates from the muscle layer in the right ventricle. The fact that we see both ventricles reaching up to the apex and forming the apex together is proof that they are approximately equal in size. If there is a condition, such as hypoplasia, in one of the ventricles, we see that this hypoplasic ventricle extends less to the apex and is less involved in the apex structure. It is also seen that it has a narrower structure in terms of its width.

\section{Evaluation of Atria}

Evaluation of the atria commences with the septum primum as mentioned above. In addition, the offset finding should be seen in the first place. In addition, the atrium dimensions must be equal. The foramen ovale and its flap should be seen clearly. At least two hypoechoic structures are seen behind and at the right and left sides of the left atrium. These are

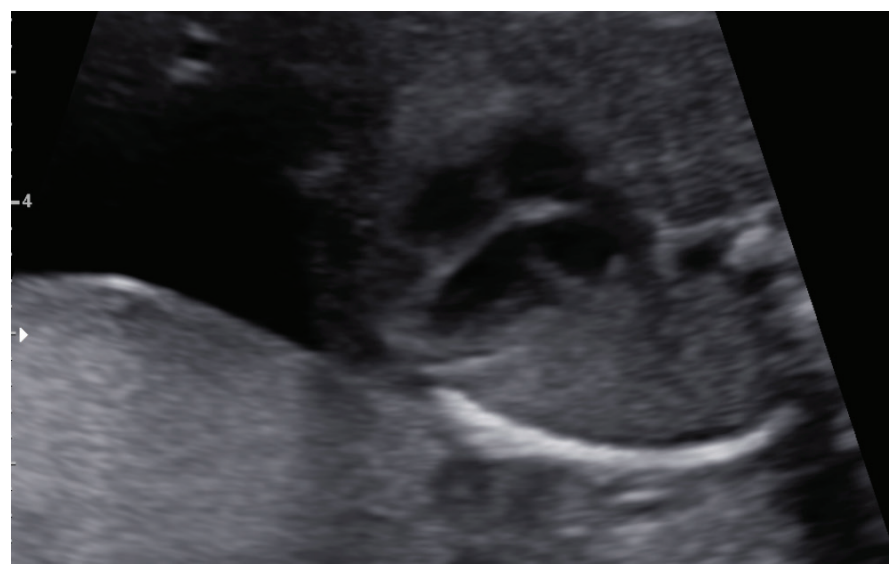

Figure 3. The four-chamber view of the heart 
four pulmonary veins that drain into the left atrium. If at least two pulmonary veins can be seen in the left atrium, the diagnosis of total pulmonary venous return anomaly is factored out. The aorta should be seen immediately behind the left atrium. In pulmonary venous return anomalies, a connecting structure should be seen between the aorta and the left atrium and behind the left atrium. Therefore, a clear evaluation of the area between the left atrium and the aorta, as well as a good determination of the points where the pulmonary veins open into the left atrium, will help to exclude pulmonary venous return anomalies.

\section{Is a Four-chamber View Sufficient?}

Only $50 \%$ of CHDs can be detected with a four-chamber examination of the heart. If the patient's examination conditions are not suitable, a four-chamber view of the heart can be satisfied. However, in this case, the patient should be informed about the situation. If the patient wants a detailed fetal heart examination, the patient should be referred to an advanced center. Anomalies that have a normal fourchamber appearance include: ${ }^{25}$ Tetralogy of Fallot (TOF), great artery transposition, double outlet right ventricle, truncus arteriosus, small ventricular and atrial septal defects, mild pulmonary stenosis and aortic stenosis, and coarctation of the aorta. To catch the pathological structure that occurs in TOF, transposition of the great arteries, double outlet right ventricle, and truncus arteriosus, it is necessary to look at the great vessel outlets. If the great vessel outlets are also examined and determined as normal, then these four anomalies will be factored out and approximately $85 \%$ of CHDs will be factored out in total. ${ }^{26}$

\section{Outflows of Great Vessels and "Three-vessel Trachea" View}

To assess the great vessel outflows, after the four-chamber view is seen, the great vessel outflows enter the image plane when the probe is slightly shifted toward the head of the fetus. ${ }^{27}$ First, it should be seen that the aorta originates from the left ventricle and that the pulmonary artery exits from the right ventricle. It should also be seen that these two veins cross each other. Similarly, when the probe is slid slightly toward the fetal head, three-vessel trachea images will appear. These images can be accessed by following the aorta outlet. There is another situation that should be mentioned here first. In the section where we see the aortic outlet, the interventricular septum should also be visible. If the interventricular septum is visible at this level, it is possible to say that the patient does not have TOF. This is called the septoaortic continuum. In cases where this condition cannot be observed, the aortic root enlarges and the aortic image, which is typical for TOF, appears. It is also possible to evaluate the size of the aorta on this axis. It is important to assess whether the aorta is too narrow or wide. Observing that the aortic valve is mobile and intact at the aortic outlet also indicates that the aortic outlet is normal (diagnoses, such as truncus arteriosus, aortic stenosis, and TOF, are excluded). After the aortic outlet is seen, it should be seen that the pulmonary artery emerges from the right ventricle and crosses over the aorta. Afterward, it can be determined that it divides into two main branches: The right and left pulmonary vein. This bifurcation, which allows us to understand that the vessel coming out of the right ventricle is the pulmonary artery, must be seen. In the case of transposition of the great artery, the cross between the aorta and the pulmonary artery cannot be traced. In this case, the veins will be traced side by side in the same plane. Sometimes this cross structure may not be seen clearly due to position defect or maternal obesity. In such cases, it is necessary to see three-vessel trachea views. This is the view of the aorta and the pulmonary artery during its course in the upper mediastinum after crossing. Threevessel trachea sections should be taken slightly above the section where the pulmonary artery and aortic outlet are seen (Figure 4). ${ }^{28}$

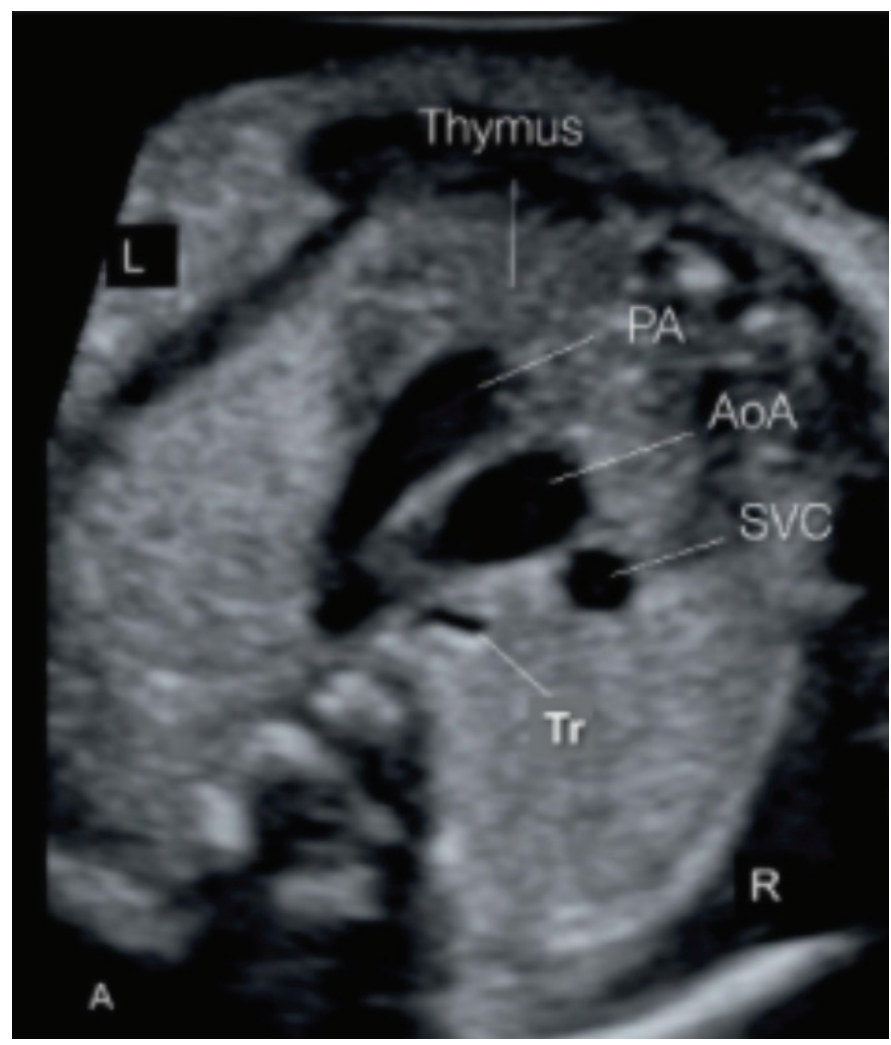

Figure 4. Ultrasonographic image of the three-vessel trachea view

PA: Pulmonary artery, AoA: Aortic arch, SVC: Superior vena cava 


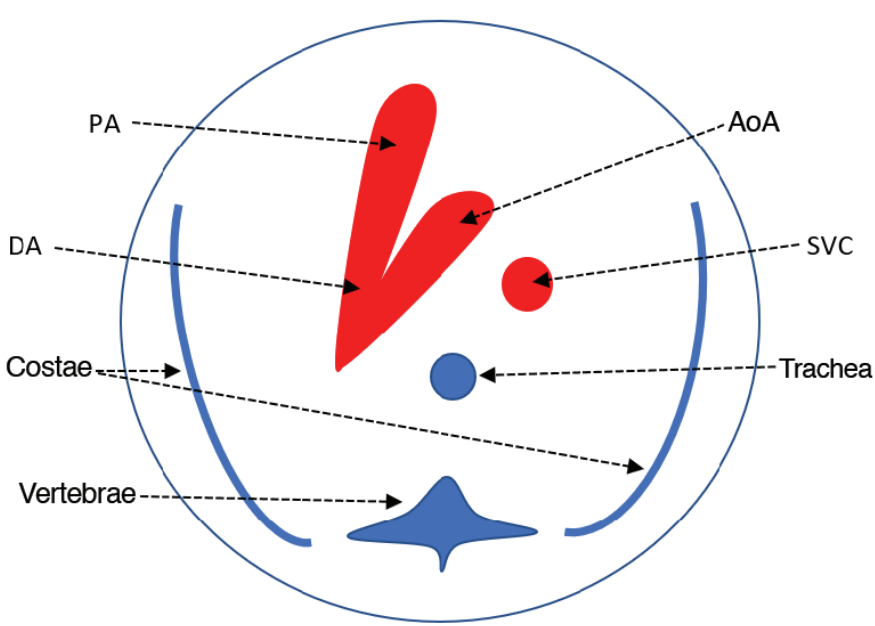

Figure 5. Schematic of the three-vessel trachea sections

PA: Pulmonary artery, AoA: Arcus aorta, DA: Ductus arteriosus, SVC: Superior vena cava

In this section, it is necessary to consider the relationship of the vessels with each other. In this section, it is necessary to see the pulmonary artery from left to right, the aorta next to it, and finally the superior vena cava at the far right. The trachea image should be seen just behind it (Figure 5). This image sequence is important. If the alignment in this image is not clear, it is a sign that there is a problem with the exit of the vessels from the heart. This image is called the V-pattern, considering its similar shape. From left to right, the two large veins should follow a $\mathrm{V}$ line. The region with two major vessel connections (the base of the V) shows the ductus arteiosus. The dimensions of these structures need to be checked. Both arms of the V-pattern should be approximately equal to each other. The pulmonary artery may be slightly enlarged relative to the aorta (arcus part of the aorta). Just to the right of this V structure, two front and back hypoechoic structures are observed. Of these structures, the superior vena cava in seen the front and the trachea is seen in the back. The more echogenic structure just in front of the three-vessel trachea structure is the thymus gland. If all these structures are visible, it can be said that there is no problem in the great vein outlets of the heart. ${ }^{29}$ If it is observed that the aorta and pulmonary artery do not form the $\mathrm{V}$ structure and that the trachea passes between them, it is necessary to suspect the right arcus aorta, that is, the DiGeorge syndrome. Even if their localization is normal, problems in the arcus aorta should be considered when there is an enlarged image of the pulmonary artery and a narrowed-thinned aorta image next to it. Aortic coarctation or interrupted arcus aorta may be present.

Fetal heart examination is an examination that can be easily performed, provided that certain algorithms are followed. It is possible to detect most of the heart anomalies if the sections that need to be seen are applied sequentially if a high-resolution ultrasound device is used, if enough time is allowed for the examination, and if the patient is evaluated with a certain level of experience. Certain major heart structures can be observed even in the first trimester. ${ }^{30,31}$ Structures, such as ventricles, atria, and interventricular septum, can be clearly observed, especially with the help of Doppler ultrasound. It is also possible to perform a heart examination in the last trimester, which is especially useful for recognizing fetal cardiac anomalies that occur in the last period. However, it involves certain difficulties. Specifically, the possibility of shadowing of the ribs increases due to the completion of ossification and this deteriorates the image quality. Depending on the progress of fetal growth, the position may not be very suitable. ${ }^{32}$

\section{CONCLUSION}

In conclusion, fetal heart examination should be conducted in every patient in clinical practice. Evaluation will be easier with a more practical approach after attaining a certain level of experience. In this way, the patient can be informed more accurately and the malpractice situations that are increasing on a daily basis can be protected.

\section{Ethics}

Peer-review: Externally peer-reviewed.

\section{Authorship Contributions}

Concept: B.S., Design: B.S., Data Collection or Processing: B.S., Analysis or Interpretation: H.G.P., Literature Search: B.S., Writing: B.S., H.G.P.

Conflict of Interest: No conflict of interest was declared by the authors.

Financial Disclosure: The authors declared that this study received no financial support.

\section{REFERENCES}

1. Rodger $M$. Evidence base for the management of venous thromboembolism in pregnancy. Hematology Am Soc Hematol Educ Program. 2010;2010:173-80.

2. Pala HGG. Fetal Kardiyak değerlendirme:Perinatolog gözüyle. Narin N, editör. Fetal Kardiyak Tanı ve Hasta Yönetimi. 1. Baskı. Ankara: Türkiye Klinikleri; 2020. p.7-15. Available from: https:// www.turkiyeklinikleri.com/article/tr-fetal-kardiyak-degerlendirmeperinatolog-gozuyle-90980.html

3. Abu-Harb M, Hey E, Wren C. Death in infancy from unrecognised congenital heart disease. Arch Dis Child. 1994;71:3-7.

4. Young ID, Clarke M. Lethal malformations and perinatal mortality: a 10 year review with comparison of ethnic differences. Br Med J (Clin Res Ed). 1987;295:89-91. 
5. Lev-Sagie A, Hamani Y, Dreman-Medina D, Holzer H, Lavy Y, Yagel S. [Prenatal diagnosis of developmental congenital malformations--the limitations of ultrasound scanning]. Harefuah. 2003;142:287-316.

6. Ge S, Maulik D. Introduction: From fetal echocardiography to fetal cardiology: A journey of over half a century. Echocardiography. 2017;34:1757-9.

7. Maulik D, Nanda NC, Maulik D, Vilchez G. A brief history of fetal echocardiography and its impact on the management of congenital heart disease. Echocardiography. 2017;34:1760-7.

8. Moon-Grady AJ, Ganesan S. The role of fetal echocardiography in the assessment of fetal aneuploidy. Clin Obstet Gynecol. 2014;57:189209.

9. David C, Doreen M, Yona A, et al. Folic acid supplementation for pregnant women and those planning pregnancy. J Clin Pharmacol. 2016;56:170-5.

10. Donofrio MT. Predicting the Future: Delivery Room Planning of Congenital Heart Disease Diagnosed by Fetal Echocardiography. Am J Perinatol. 2018;35:549-52.

11. Sanapo L, Pruetz JD, Słodki M, Goens MB, Moon-Grady AJ, Donofrio MT. Fetal echocardiography for planning perinatal and delivery room care of neonates with congenital heart disease. Echocardiography. 2017;34:1804-21.

12. D'Alton M, Mercer B, Riddick E, Dudley D. Serial thoracic versus abdominal circumference ratios for the prediction of pulmonary hypoplasia in premature rupture of the membranes remote from term. Am J Obstet Gynecol. 1992;166:658-63.

13. Small M, Copel JA. Indications for fetal echocardiography. Pediatr Cardiol. 2004;25:210-22.

14. Pala HG. Twin-Twin Transfusion Syndrome: Impact on cardiovascular System. in: Sen C,Stanojevic M eds. Fetal Heart. Screening, Diagnosis and intervention. 1st ed. New Delhi: Jaypee Brothers medical Publishers; 2020. p.178-90.

15. Yoshimura S, Masuzaki H, Gotoh H, Fukuda H, Ishimaru T. Ultrasonographic prediction of lethal pulmonary hypoplasia: comparison of eight different ultrasonographic parameters. Am J Obstet Gynecol. 1996;175:477-83.

16. Sen C, Yayla M. Fetal Heart Examination. In:Sen C, Stanojevic M eds. Fetal Heart. Screening, Diagnosis and Intervention. Ist ed. New Delhi: Jaypee Brothers medical Publishers; 2020. P. 26-53.

17. Smith RS, Comstock CH, Kirk JS, Lee W. Ultrasonographic left cardiac axis deviation: a marker for fetal anomalies. Obstet Gynecol. 1995;85:187-91.

18. Comstock $\mathrm{CH}$. Normal fetal heart axis and position. Obstet Gynecol. 1987;70:255-9.
19. Yuan SM. Fetal arrhythmias: Surveillance and management. Hellenic J Cardiol. 2019;60:72-81.

20. ACOG Practice Bulletin No. 106: Intrapartum fetal heart rate monitoring: nomenclature, interpretation, and general management principles. Obstet Gynecol. 2009;114:192-202.

21. Yeom W, Paik ES, An JJ, et al. Clinical characteristics and perinatal outcome of fetal hydrops. Obstet Gynecol Sci. 2015;58:90-7.

22. Yavuz A, Akkurt MO, Yalcin S, Karakoc G, Varol E, Sezik M. Second Trimester Fetal and Maternal Epicardial Fat Thickness in Gestational Diabetic Pregnancies. Horm Metab Res. 2016;48:595-600.

23. International Society of Ultrasound in Obstetrics and Gynecology. Carvalho JS, Allan LD, et al. ISUOG Practice Guidelines (updated) sonographic screening examination of the fetal heart. Ultrasound Obstet Gynecol. 2013;41:348-59.

24. Kirk JS, Comstock CH, Lee W, Smith RS, Riggs TW, Weinhouse E. Fetal cardiac asymmetry: a marker for congenital heart disease. Obstet Gynecol. 1999;93:189-92.

25. Bravo-Valenzuela NJ, Peixoto AB, Araujo Júnior E. Prenatal diagnosis of congenital heart disease: A review of current knowledge. Indian Heart J. 2018;70:150-64.

26. Yoo SJ, Lee YH, Kim ES, et al. Three-vessel view of the fetal upper mediastinum: an easy means of detecting abnormalities of the ventricular outflow tracts and great arteries during obstetric screening. Ultrasound Obstet Gynecol. 1997;9:173-82.

27. Yagel S, Cohen SM, Achiron R. Examination of the fetal heart by five short-axis views: a proposed screening method for comprehensive cardiac evaluation. Ultrasound Obstet Gynecol. 2001;17:367-9.

28. Obgynkey. The Three-Vessel-Trachea View and Upper Mediastinum. Available from: https://obgynkey.com/the-three-vessel-tracheaview-and-upper-mediastinum

29. Yagel S, Arbel R, Anteby EY, Raveh D, Achiron R. The three vessels and trachea view (3VT) in fetal cardiac scanning. Ultrasound Obstet Gynecol. 2002;20:340-5.

30. McBrien A, Hornberger LK. Early fetal echocardiography. Birth Defects Res. 2019;111:370-9.

31. Carvalho JS, Moscoso G, Tekay A, Campbell S, Thilaganathan B, Shinebourne EA. Clinical impact of first and early second trimester fetal echocardiography on high risk pregnancies. Heart. 2004;90:921-6.

32. Pala HG. Fetal cardiac function in normal and growth restricted fetuses. in: Sen C, Stanojevic M eds. Fetal Heart. Screening. Diagnosis and intervention. Ist ed. New Delhi: Jaypee Brothers medical Publishers; 2020;p.156-66. 